Check for updates

Cite this: RSC Adv., 2017, 7, 37181

\title{
Alternating magnetic field mediated micro reaction system for palladium-catalyzed coupling reactions $\uparrow$
}

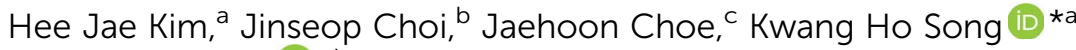 \\ and Sunwoo Lee (iD)*b
}

Received 3rd July 2017

Accepted 21st July 2017

A continuous flow reaction system in which a palladium magnetic catalyst was immobilized and vibrated by an alternating induced magnetic field was developed. The alternating electromagnetic field improved the mixing efficiency and catalytic activity for the palladium-catalyzed coupling reactions. This flow reaction system showed good product yields for various reactions such as Sonogashira, Heck, Suzuki, Stille, Hiyama and decarboxylative coupling reactions.

rsc.li/rsc-advances

catalyst on the flow reactor. Most cases have borrowed tools that

Transition metal-catalyzed transformations are one of the most versatile synthetic tools in organic synthesis. ${ }^{1}$ In particular, coupling reactions catalyzed by late transition metals such as palladium, copper, and nickel have been widely used to construct important organic building blocks in pharmaceutical and materials chemistry. ${ }^{2}$ The development of palladiumcatalyzed coupling reactions was awarded the Nobel Prize in Chemistry in $2010 .^{3}$

The considerable attention paid to green chemistry has triggered a need to develop of environmentally friendly chemical processes. To meet this demand, recyclable catalytic systems with immobilized catalysts have been developed for organic transformations that proceed via homogeneous catalysis. ${ }^{4}$ The most common method for immobilization of catalysts uses polymer or inorganic supports bearing ligands that can bind to the metal catalyst. To make the process for recycling the catalyst easier, magnetic particles were employed and encapsulated by the immobilized catalyst. ${ }^{5}$

The continuous flow reaction system has been developed and applied to a variety of transition metal-catalyzed transformations. ${ }^{6}$ Compared with traditional batch reactions, this continuous flow chemistry has several benefits, including excellent mass transfer and thermal control due to the high surface-to-volume area. Moreover, continuous flow systems can be easily scaled by using parallel reactors. To apply this continuous flow reaction system in metal-catalyzed transformations, the most important factor is the immobilization of

\footnotetext{
${ }^{a}$ Department of Chemical \& Biological Engineering, Korea University, Seoul 02841, Republic of Korea.E-mail: khsong@korea.ac.kr

${ }^{b}$ Department of Chemistry, Chonnam National University, Gwangju, 61186, Republic of Korea.E-mail: sunwoo@chonnam.ac.kr ${ }^{c}$ LG Chem Research Park, Daejeon 34122, Republic of Korea

$\dagger$ Electronic supplementary information (ESI) available. See DOI: $10.1039 / \mathrm{c} 7 \mathrm{ra07324k}$
}

were established in batch reaction systems. One of the most frequently used methods is the immobilization of the catalyst on polymer or inorganic supports packed in the channel of the flow reactor. ${ }^{7}$ However, this catalytic packing system gave rise to a backpressure owing to the high volume of supporting materials. As a solution to solve this problem, the immobilization of the catalyst on magnetic particles was employed in the reaction flow system (Fig. 1a). ${ }^{8}$ However, with this method, only a small portion of the reagents might encounter the catalyst particles, and the efficiency of the reaction is very low because the catalyst is immobilized on the surface of the channel by a magnetic field.

To address these issues, we introduced an alternating magnetic field into the continuous flow reaction system with palladium magnetic particles as an immobilized catalyst. In addition, to arrange and vibrate the catalyst in the reaction channel, the induced magnetic field was periodically changed to improve the mixing efficiency. For microfluidic systems, some simulations have been reported for magnetic particles in an induced magnetic field and showed improved mixing

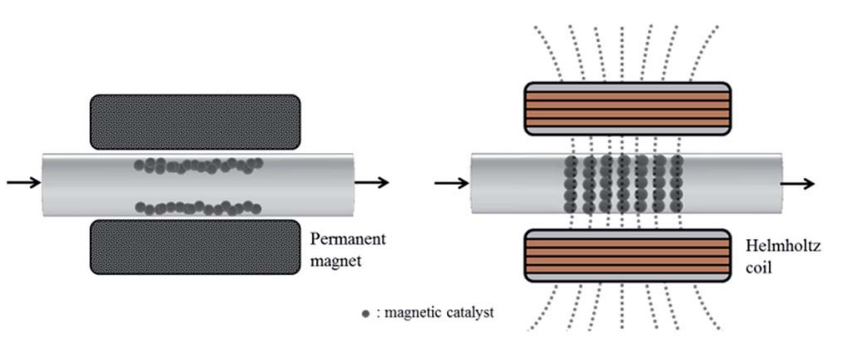

(a)

(b)

Fig. 1 (a) Continuous flow reactor with a magnetic catalyst and an external permanent magnet; (b) electromagnetic micro-reactor with a magnetic catalyst and a Helmholtz coil using alternating current. 
efficiency for electromagnetic micro reactors. Here, we report the continuous flow reactions using an immobilized magnetic palladium catalyst under an induced magnetic field (Fig. 1b).

To achieve our goal, we attempted to optimize conditions such as catalyst particle size, flow rate, and strength and frequency of the magnetic field. It is important to find conditions under which the catalyst particles stay in the reaction channel with the appropriate flow rate without loss of particles. To determine the optimal particle size and flow rate, we chose four different sizes of magnetic palladium particles and investigated the relationship between particle size, magnetic field strength, and flow rate of the reaction mass. As most of the catalyst particle consists of iron oxide, the size of the catalyst particles was controlled by using iron oxides of different sizes. The same amount of magnetic particles to each four different sizes injected to $1 / 16$ inch channel. It tested whether magnetic particles are spilled out from the channel in the condition of $400 \mathrm{G}$ and $560 \mathrm{G}$ at various flow rates. As shown in Fig. 2, 0.3 and $1 \mu \mathrm{m}$ particles did not stay in the reaction channel under flow rates in the range of $4-30 \mu \mathrm{L} \min ^{-1}$ in either 400 or $560 \mathrm{G}$ magnetic fields. The $15 \mu \mathrm{m}$ particles were retained in the reaction channel under a flow rate of $12 \mu \mathrm{L} \mathrm{min}{ }^{-1}$ in a $560 \mathrm{G}$ magnetic field. The $70 \mu \mathrm{m}$ particles did not stay in the reaction channel under a flow rate of $28 \mu \mathrm{L} \mathrm{min}{ }^{-1}$. When the flow rate was decreased to $20 \mu \mathrm{L} \mathrm{min}{ }^{-1}$, the $70 \mu \mathrm{m}$ particles were retained in the reaction channel in a $560 \mathrm{G}$ magnetic field, but not in a $400 \mathrm{G}$ magnetic field. However, the $70 \mu \mathrm{m}$ particles were retained at a flow rate of $14 \mu \mathrm{L} \mathrm{min}{ }^{-1}$ in both 400 and $560 \mathrm{G}$ magnetic fields. In retention range of Fig. 2, we found that this flow system hold $98 \%$ of the catalyst during $1.5 \mathrm{~h}$.

From the above experiment, a magnetic field of at least $560 \mathrm{G}$ is required to retain $15 \mu \mathrm{m}$ in the reaction channel. We conducted a Villermaux-Dushman reaction., ${ }^{\mathbf{9}, 10}$ to observe the change in mixing efficiency of the electromagnetic microreactor at various magnetic fields and frequencies. The results of the Villermaux-Dushman reaction experiment, as shown in Fig. 3, indicate that magnetic particles move more at high frequencies than at low frequencies and move further at high intensities than at low intensities. For the Helmholtz coil, the magnitude of magnetic flux density and frequency are inversely proportional area. Equations that show the relation of the magnitude of magnetic flux density and the frequency are displayed in Fig. 3. Accordingly, the experiment had to be conducted in a fanshaped. In this area, we chose the condition that has better mixedness ratio than the darker area, and carried out the experiments in the condition of marked point $(5 \mathrm{~Hz}, 560 \mathrm{G})$.

With this result in hand, we chose to use $15 \mu \mathrm{m}$ magnetic particles to prepare the magnetic palladium catalyst using a well-established method. ${ }^{11}$ These magnetic catalyst particles were packed in a flow reaction tube, which was placed in a Helmholtz coil, as shown Fig. 4.

To evaluate the magnetic flow reaction system, Sonogashira coupling reaction was tested using flow reaction systems with either permanent magnet or the Helmholtz coil. As shown in Table 1, phenylacetylene and iodobenzene were reacted under a variety of conditions. With increasing temperature, the product yields were increased in both cases (entries 1-3). As

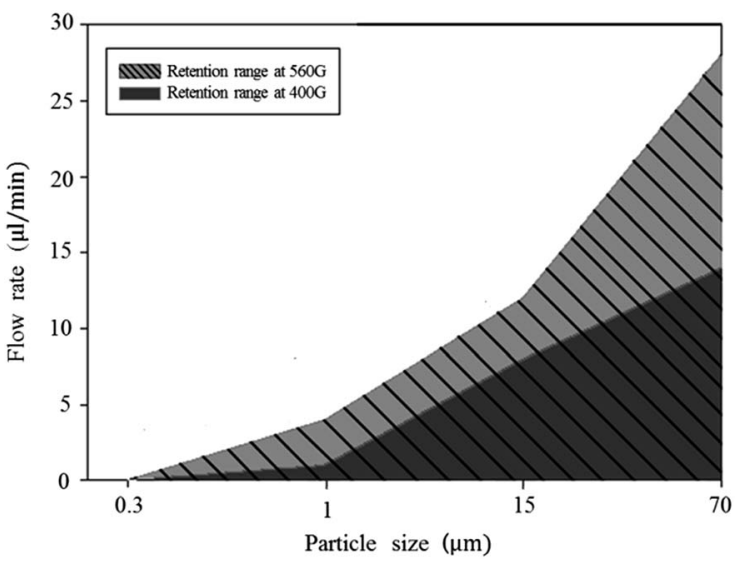

Fig. 2 Retention range according to magnetic field intensity, the flow rate and particle size.

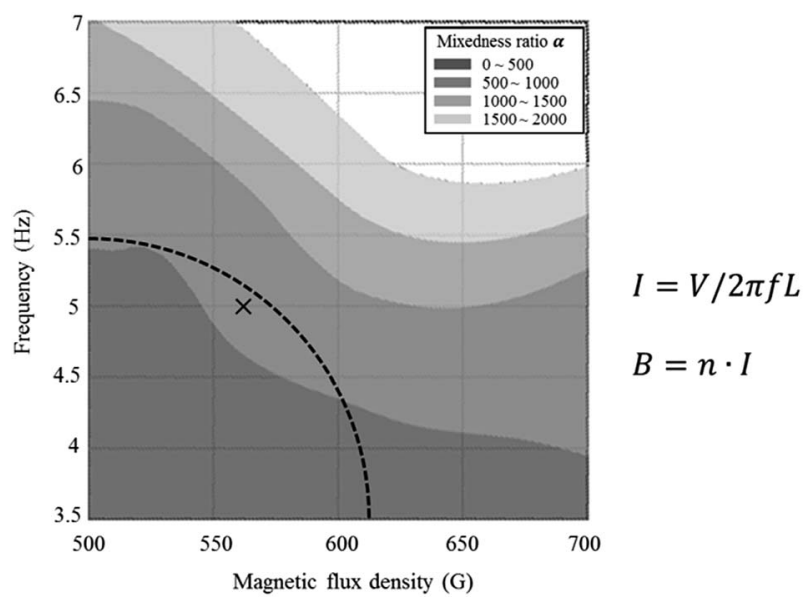

Fig. 3 Mixing performance according to magnetic field intensity and frequency $(/$ is the current, $V$ is the voltage, $f$ is the frequency, $L$ is the inductance, $B$ is the magnitude of magnetic field, $n$ is the number of turns in the coil).

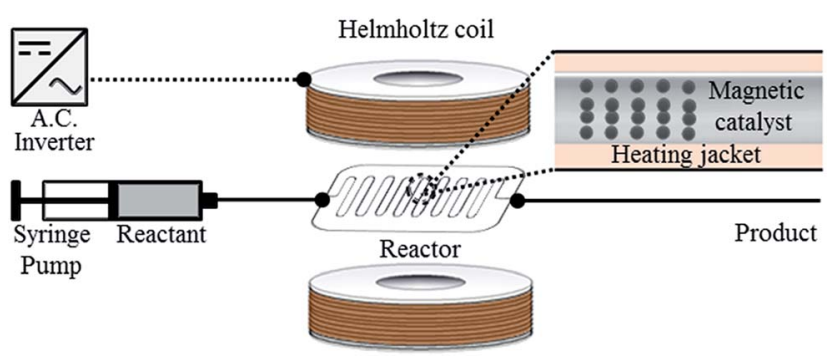

Fig. 4 Schematic figure of electromagnetic micro reactor.

expected, the Helmholtz coil system showed higher yields than the permanent magnet system. With organic bases such as $\mathrm{Et}_{3} \mathrm{~N}$ and DBU, the Helmholtz coil system afforded the desired product, but no desired product was formed using the permanent magnet system (entries 4 and 5).

Using this condition, various aryl iodides were employed in this flow reaction system. As shown in Scheme 1, iodotoluenes 
Table 1 Sonogashira reaction in a continuous flow reaction system under alternating and permanent magnetic fields ${ }^{a}$

Eeaction
System

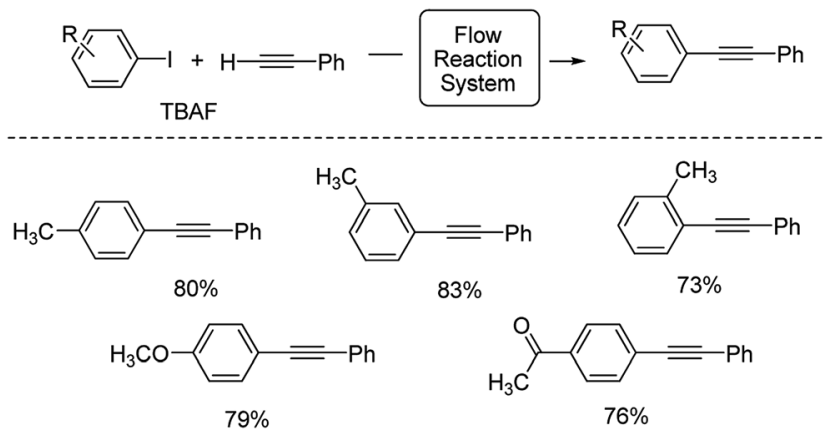

Scheme 1 Sonogashira coupling reaction using the flow reaction system.

underwent this reaction with good products. Aryl iodides bearing electron-donating and electron-withdrawing groups also afforded the desired products in good yields.

To expand this flow reaction system, a variety of coupling reactions were employed (Table 2). Heck reaction provided the desired product with $85 \%$ yield (entry 1). Suzuki, Stille and Hiyama coupling reactions afforded 4-methylbiphenyl with $74 \%, 87 \%$ and $95 \%$ yields, respectively (entries $2-4$ ). In addition, a decarboxylative coupling reaction with phenyl propiolic acid gave diphenyl acetylene with $85 \%$ yield (entry 5 ). ${ }^{\mathbf{1 2}}$

In summary, we developed a flow reaction system in which immobilized palladium magnetic particles act as a catalyst in an electromagnetic microreactor using a Helmholtz coil with alternating current. We studied the relationship between magnetic particle size, flow rate, and strength of magnetic field

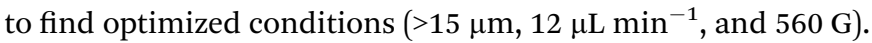
This flow reaction system showed good catalytic activities for palladium-catalyzed coupling reactions such as Sonogashira,
Table 2 Coupling reaction using flow reaction system ${ }^{a}$

\begin{tabular}{|c|c|c|c|c|}
\hline Entry & Reactant $1 /$ reactant 2 & Base & Product & $\begin{array}{l}\text { Yield }^{b} \\
(\%)\end{array}$ \\
\hline 1 & $\mathrm{C}_{6} \mathrm{H}_{5} \mathrm{I} / \mathrm{CH}_{2} \mathrm{CHCO}_{2}(n-\mathrm{Bu})$ & $\mathrm{Et}_{3} \mathrm{~N}$ & & 85 \\
\hline 2 & $4-\mathrm{MeC}_{6} \mathrm{H}_{4} \mathrm{I} / \mathrm{C}_{6} \mathrm{H}_{5} \mathrm{~B}(\mathrm{OH})_{2}$ & $\mathrm{Et}_{3} \mathrm{~N}$ & & 74 \\
\hline 3 & $4-\mathrm{MeC}_{6} \mathrm{H}_{4} \mathrm{I} / \mathrm{C}_{6} \mathrm{H}_{5} \mathrm{SnBu}_{3}$ & - & & 87 \\
\hline 4 & $4-\mathrm{MeC}_{6} \mathrm{H}_{4} \mathrm{I} / \mathrm{C}_{6} \mathrm{H}_{5} \mathrm{Si}(\mathrm{OEt})_{3}$ & TBAF & & 95 \\
\hline 5 & $\mathrm{C}_{6} \mathrm{H}_{5} \mathrm{I} / \mathrm{C}_{6} \mathrm{H}_{5} \mathrm{CCCO}_{2} \mathrm{H}$ & TBAF & & 85 \\
\hline $\begin{array}{l}{ }^{a} \text { Reac } \\
\text { and b } \\
\text { Magn } \\
\text { reside } \\
\text { chrom }\end{array}$ & $\begin{array}{l}\text { tion conditions: reactant } 1 \\
\text { ase }(0.2 \mathrm{mmol}) \text { were diss } \\
\text { tic catalyst }(0.125 \mathrm{~mol} \% \mathrm{~b} \\
\text { ace time: } 90 \text { min. } \\
\text { atography. }\end{array}$ & $\begin{array}{l}1 \text { (0.1 } \\
\text { solved } \\
\text { based o } \\
\text { Yields }\end{array}$ & $\begin{array}{l}\text { amol), re } \\
\text { in DMF } \\
\text { n Pd); fl } \\
\text { were }\end{array}$ & $\begin{array}{l}\text { mmol), } \\
\text { flowed. } \\
\min ^{-1} \text {; } \\
\text { by gas }\end{array}$ \\
\hline
\end{tabular}

Heck, Suzuki, Stille, Hiyama and decarboxylative coupling reactions. In addition, all reactions could be scalable by using parallel reactors.

\section{Acknowledgements}

This research was supported by the National Research Foundation of Korea (NRF) grant funded by the Korea government (NRF-2012R1A1A2044286 and NRF-2015R1A4A1041036).

\section{Notes and references}

1 (a) L. Haughton and J. M. J. Williams, J. Chem. Soc., 1999, 1, 2645; (b) B. C. G. Soderberg, Coord. Chem. Rev., 2003, 247, 79.

2 (a) A. Brennfuhrer, H. Neumann and M. Beller, Angew. Chem., Int. Ed., 2009, 48, 4114; (b) R. Martin and S. L. Buchwald, Acc. Chem. Res., 2008, 41, 1461.

3 C. C. C. J. Seechurn, M. O. Kitching, T. J. Colacot and V. Snieckus, Angew. Chem., Int. Ed., 2012, 51, 5062.

4 (a) B. M. Trost, Angew. Chem., Int. Ed., 1995, 34, 259; (b) I. Angurell, G. Muller, M. Rocamora, O. Rossell and M. Seco, Dalton Trans., 2003, 6, 1194; (c) B. C. Ranu, S. Bhadra and D. Saha, Curr. Org. Synth., 2011, 8, 146; (d) N. Nami and N. Nami, J. Chem., Biol. Phys. Sci., 2015, 5, 1195. 5 (a) D. Astruc, F. Lu and J. R. Aranzaes, Angew. Chem., Int. Ed., 2005, 44, 7852; (b) R. B. Bedford, M. Betham, D. W. Bruce, S. A. Davis, R. M. Frost and M. Hird, Chem. Commun., 2006, 13, 1398; (c) C. P. Park and D. P. Kim, Angew. Chem., Int. Ed., 2010, 49, 6825; (d) P. Li, L. Wang, L. Zhang and G.-W. Wang, Adv. Synth. Catal., 2012, 354, 1307; (e) L. Zhang, P. Li, J. Yang, M. Wang and L. Wang, 
ChemPlusChem, 2014, 79, 217; (f) L. Zhang, P. Li, H. Li and L. Wang, Catal. Sci. Technol., 2012, 2, 1859.

6 (a) A. Nagaki, A. Kenmoku, Y. Moriwaki, A. Hayashi and J. I. Yoshida, Angew. Chem., Int. Ed., 2010, 49, 7543; (b) J. P. McMullen, M. T. Stone, S. L. Buchwald and K. F. Jensen, Angew. Chem., Int. Ed., 2010, 49, 7076; (c) T. Noël, S. Kuhn, A. J. Musacchio, K. F. Jensen and S. L. Buchwald, Angew. Chem., Int. Ed., 2011, 50, 6065; (d) T. Noël, J. R. Naber, R. L. Hartman, J. P. McMullen, K. F. Jensen and S. L. Buchwald, Chem. Sci., 2011, 2, 287; (e) D. Obermayer, A. M. Balu, A. A. Romero, W. Goessler, R. Luque and C. O. Kapper, Green Chem., 2013, 15, 1530; $(f)$ D. Cantillo and C. O. Kappe, ChemCatChem, 2014, 6, 3286; (g) R. Munirathhinam, J. Huskens and W. Verboom, Adv. Synth. Catal., 2015, 357, 1093; (h) M. Brzozowski, J. A. Forni, G. P. Savage and A. Polyzos, Chem. Commun., 2015, 51, 334; (i) H. Lebel, H. Piras and M. Borduy, ACS Catal., 2016, 6, 1109.

7 (a) C. G. Chang, B. K. Paul, V. T. Remcho, S. Atre and J. E. Hutchison, J. Nanopart. Res., 2008, 10, 965; (b) U. Laska, C. G. Frost, G. J. Price and P. K. Plucinski, J. Catal., 2009, 268, 318; (c) N. J. S. Costa, P. K. Kiyohara,
A. L. Monteiro, Y. Coppel, K. Philippot and L. M. Rossi, J. Catal., 2010, 276, 382; (d) X. Zhang, P. Li, Y. Ji, L. Zhang and L. Wang, Synthesis, 2011, 18, 2975; (e) K. Terao, Y. Nishiyama, H. Tanimoto, T. Morimoto, M. Oelgemoller and K. Kakiuchi, J. Flow Chem., 2012, 2, 73; (f) L. B. Escudero, R. A. olsina and R. G. Wuilloud, Talanta, 2013, 116, 133; (g) D. Cantillo and C. O. Kappe, ChemCatChem, 2016, 6, 3286.

8 (a) M. N. Moore, M. Andrade, A. N. Scozzari and A. H. Krotz, Org. Process Res. Dev., 2004, 8, 271; (b) E. V. Alonso, M. D. M. Guerrero, P. C. Cueto, J. B. Benitez, J. M. C. Pavon and A. G. D. Torres, Talanta, 2016, 153, 228.

9 J. M. Commenge and L. Falk, Chem. Eng. Proc., 2011, 50, 979. 10 See ESI $(\mathrm{S} 1 \dagger)$ for the detailed process of VillermauxDushman reaction.

11 See ESI (S2 $\dagger$ ) for the detailed synthetic procedure fo catalytic magnetic particle.

12 (a) J. Moon, M. Jeong, H. Nam, J. Ju, J. H. Moon, H. M. Jung and S. Lee, Org. Lett., 2008, 10, 945; (b) J. Moon, M. Jang and S. Lee, J. Org. Chem., 2009, 74, 1403; (c) H. Kim and P. H. Lee, Adv. Synth. Catal., 2009, 351, 2827; (d) K. Park and S. Lee, RSC Adv., 2013, 3, 14165. 